\title{
A Study of Service Quality Management on Health Care Industry in Bangalore
}

\author{
H. S. Murthy \\ 434, 8thMain, Vijaya Bank Layout, Bangalore560076
}

\section{International and National Scenario}

USA::

Health care spending in America accounts for a larger share of GDP than in any other country Health spending in the U.S., at about $17.5 \%$ of Gross Domestic Product (GDP) in 2010, is projected to grow to about $20 \%$ by 2020 . Despite the incredible investment America continues to make in health care, $16.7 \%$ of people in the U.S. (50.7 million people, up from 46.3 million the previous year) lacked health care coverage for the entire year of 2009. For some, insurance was unavailable or unaffordable. In other cases, a lack of insurance was due to a personal decision not to pay for it.

II. Other Countries:

A comprehensive study published by the OECD (Organization for Economic Cooperation \& Development) in 2010, covering more than 30 nations including the majority of the world's most developed economies (but not Brazil, Russia, India or China), found stark contrasts between health costs in the United States and those of other nations. In 2008 (the latest complete data available), the average of a list that includes, for example, the U.K., France, Germany, Mexico, Canada, South Korea, Japan, Australia and the U.S., spent 9.0\% of GDP on health care. France at $11.2 \%$ and Switzerland at $10.7 \%$. Health expenditures per capita, on a purchasing power-adjusted basis (PPP), averaged $\$ 3,000$.

Total health care expenditures around the world are difficult to determine, but $\$ 5.5$ trillion would be a fair estimate for 2010. That would place health care at about $8 \%$ of global GDP, with expenditures per capita about $\$ 800$. This $\$ 5.4$ trillion breaks down to approximately $\$ 2.6$ trillion in the U.S., $\$ 2.4$ trillion in non-U.S. OECD nations, and $\$ 0.5$ trillion elsewhere around the world. Outside the U.S. and the rest of the OECD, that would allow roughly $\$ 88$ per capita per year. Clearly, there is vast disparity in the availability and cost of care among nations, as there is with personal income and GDP. Health care spending per capita in the U.S. was equal to about $\$ 8,290$ in 2010 , while spending in the world's remotest villages was next to nothing. The trend over the near future is for the modest amount now spent on health care in emerging nations to rise dramatically, while OECD nations like America struggle to contain their own mountainous costs. Globally, the total prescription drug market was in the $\$ 630$ billion range in 2010.

\section{Critical Partners: Employers, Employees And Insurer's, Healthcare Providers} Perspectives:

Many major employers are utilizing unique new programs in efforts to reduce employee illness, and thereby reduce costs. For example, the use of preventive care programs is growing, as is the use of employee education aimed at better managing the effects of diseases such as diabetes.

Patients and insurance companies are also dealing with sticker shock over the nation's prescription drug costs. Other factors edging costs upward include expensive new medical technologies and patients' demands for greater plan flexibility in choosing doctors and specialists at their will. At the same time, hospitals and health systems write off massive amounts of revenues to bad debt, which increases costs for bill-paying patients.

In the wake of the tremendous growth of all aspects of the health care industry from the end of World War II onward, efficiency, competition and productivity were, regretfully, largely overlooked. Much of this occurred because employers plus federal and state governments paid such a large portion of the health care bill.

Physicians are caught between the desire to provide quality care and the desire for cost control on the part of payers, including PPOs, Medicare and Medicaid. The cost versus care debate has spawned an energetic movement to improve the quality of health care in the U.S., much of it centered on patients' rights, disease management, preventive health care and patient education. Nonetheless, wellness programs, preventive medicine and health education remain woefully inadequate. One of the main differences between the health care system of India and USA is the greater role of the states in health care provision 


\section{Indian Governmental Efforts \& Primary Healthcare:}

Healthcare in India features a universal health care system run by the constituent states and territories of India. The Constitution charges every state with "rising of the level of nutrition and the standard of living of its people and the improvement of public health as among its primary duties". The National Health Policy was endorsed by the Parliament of India in 1983 and updated in 2002. However, the government sector is understaffed and underfinanced; poor services at state-run hospitals force many people to visit private medical practitioners.

Government hospitals, some of which are among the best hospitals in India, provide treatment at taxpayer expense. Most essential drugs are offered free of charge in these hospitals. Government hospitals provide treatment either free or at minimal charges. For example, an outpatient card at AIIMS (one of the best hospitals in India) costs a one time fee of rupees 10 (around 20 cents US) and thereafter outpatient medical advice is free. In-hospital treatment costs depend on financial condition of the patient and facilities utilized by him The charges for basic in-hospital treatment and investigations are much less compared to the private sector. The cost for these subsidies comes from annual allocations from the central and state governments.

Primary health care is provided by city and district hospitals and rural primary health centres (PHCs). These hospitals provide treatment free of cost. Primary care is focused on immunization, prevention of malnutrition, pregnancy, child birth, postnatal care, and treatment of common illnesses. Patients who receive specialized care or have complicated illnesses are referred to secondary (often located in district and taluk headquarters) and tertiary care hospitals (located in district and state headquarters or those that are teaching hospitals).

Primary health centers are the cornerstone of the rural health care system. These facilities are part of a tiered health care system that funnels more difficult cases into urban hospitals while attempting to provide routine medical care to the vast majority in the countryside. Primary health centers and sub centers rely on trained paramedics to meet most of their needs. The main problems affecting the success of primary health centers are the predominance of clinical and curative concerns over the intended emphasis on preventive work and the reluctance of staff to work in rural areas. In addition, the integration of health services with family planning programs often causes the local population to perceive the primary health centers as hostile to their traditional preference for large families. Therefore, primary health centers often play an adversarial role in local efforts to implement national health policies.

\section{Status Of Indian Healthcare System:}

$\mathrm{T}$ he Indian healthcare industry is seen to be growing at a rapid pace and is expected to become a US $\$ 280$ billion industry by 2020 The Indian healthcare market was estimated at US $\$ 35$ billion in 2007 and is expected to reach over US $\$ 70$ billion by 2012 and US $\$ 145$ billion by 2017 [3]. According to the Investment Commission of India the healthcare sector has experienced phenomenal growth of 12 percent per annum in the last 4 years [4]. Rising income levels and a growing elderly population are all factors that are driving this growth. In addition, changing demographics, disease profiles and the shift from chronic to lifestyle diseases in the country has led to increased spending on healthcare delivery [5].

Even so, the vast majority of the country suffers from a poor standard of healthcare infrastructure which has not kept up with the growing economy. Despite having centers of excellence in healthcare delivery, these facilities are limited and are inadequate in meeting the current healthcare demands. Nearly one million Indians die every year due to inadequate healthcare facilities and 700 million people have no access to specialist care and $80 \%$ of specialists live in urban areas.[6]

\section{Indian Healthcare: Challenges \& Prospects:}

On the one hand, the Indian middle class, with its increasing purchasing power, is more willing than ever before to pay more for quality healthcare. On the other, the supply of healthcare services has grown steadily, as the private sector becomes more involved in owning and running hospitals

Indian healthcare industry is fairly insulated from global recession and slowdown in the Indian economy and healthy enough to grow at the rate of $15 \%$ over the period of next 10 years, reveals a report on healthcare sector released by Confederation of Indian Industry (CII) and Grant Thornton India.

In order to meet manpower shortages and reach world standards India would require investments of up to $\$ 20$ billion over the next 5 years Forty percent of the primary health centers in India are understaffed. According to WHO statistics there are over 250 medical colleges in the modern system of medicine and over 400 in the Indian system of medicine and homeopathy (ISM\&H). India produces over 250,000 doctors annually in the modern system of medicine and a similar number of ISM\&H practitioners, nurses and para professionals Better policy regulations and the establishment of public private partnerships are possible solutions to the problem of manpower shortage. 
India faces a huge need gap in terms of availability of number of hospital beds per 1000 population. With a world average of 3.96 hospital beds per 1000 population India stands just a little over 0.7 hospital beds per 1000 population.. Moreover, India faces a shortage of doctors, nurses and paramedics that are needed to propel the growing healthcare industry. India is now looking at establishing academic medical centers (AMCs) for the delivery of higher quality care with leading examples of The Manipal Group \& All India Institute of Medical Sciences (AIIMS) already in place.

As incomes rise and the number of available financing options in terms of health insurance policies increase, consumers become more and more engaged in making informed decisions about their health and are well aware of the costs associated with those decisions. In order to remain competitive, healthcare providers are now not only looking at improving operational efficiency but are also looking at ways of enhancing patient experience overall.

India has approximately 600,000 allopathic doctors registered to practice medicine. This number however, is higher than the actual number practicing because it includes doctors who have immigrated to other countries as well as doctors who have died. India licenses 18,000 new doctors a year.

According to data provided in 1989 by the Ministry of Health and Family Welfare, the total number of civilian hospitals for all states and union territories combined was 10,157. In 1991 there were a total of 811,000 hospital and health care facilities beds. The geographical distribution of hospitals varied according to local socioeconomic conditions. In India's most populous state, Uttar Pradesh, with a 1991 population of more than 139 million, there were 735 hospitals as of 1990. In Kerala, with a 1991 population of 29 million occupying an area only one-seventh the size of Uttar Pradesh, there were 2,053 hospitals.

\section{Medical tourism in India: Future trends}

However, at the same time, India's health care system also includes entities that meet or exceed international quality standards. The medical tourism business in India has been growing in recent years and as such India is a popular destination for medical tourists who receive effective medical treatment at lower costs than in developed countries

A recent forecast by deloitte Consulting published in August 2008 projected that medical tourism originating in the US would increase over ten times than what is it currently, in the next decade. An estimated 750,000 Americans outsourced their health care in 2007, and the report estimated around 1.5 million US patients would be medical tourists who would be getting their surgery done abroad. this outsourcing will be broadly led by low cost of healthcare in the developing countries, excellent infrastructure in terms of medical and surgical care, the long waiting time in their local markets coupled with insurers that do not cover certain surgeries.

\section{Responding to Customers' needs}

A system for $a b$ initio identification and correction of errors is also important for quality services. Customers who are recipients of defective service often quickly reconcile themselves to shoddy services out of sheer despair and do not bother to report them. Keeping nicely printed forms is not sufficient particularly in the Indian context when there is poor credibility of services! Customers do not just believe that any improvement will come and hence they merely turn cynical. On the other hand, sincere response to the customers even in small matters earns a lot of goodwill. For example, a well reputed hotel in Coimbatore is known for immediate action against their employees who take customer service lightly.

Since there is an enormous gap in the availability of services, customers in developing countries are not at all demanding. Even normal services are considered a great boon. For instance, a flight arrival at the scheduled time is considered a great obligation done to the passengers Consistency and predictability are important aspects in the services sector.

Planning for the growth of quality services is by itself a big task in the developing countries. For example, electric supply to industries or water supply in towns and cities to a burgeoning population is not an easy task. In a developing society, since the purchasing power of people is low, there is an expectation of service at a low cost. However, by now, the realization has dawned that a good service organized at a reasonable cost is definitely worth having. For example, even for a pay and use latrine in a bus stand, more and more people are willing to pay, as long it is reasonably well maintained. The work of Sulabh International deserves special mention in this regard.

Peter Drucker, the world famous management guru, predicts that the organization pattern in the services sector will be such that unlike the traditional pyramidal organization, they will be flatter with more responsibility at the lower rungs for their respective areas of functioning

\section{Bangalore in the Indian Healthcare Map:}

Since the 90s and more recently, the healthcare sector has witnessed corporatization in a big way .Bangalore, as a fastest growing city, has grown huge in the last 15 years, with Bangalore having been recognized as the silicon city(not valley) of India. With the amalgamation of vast areas from the hither-to Rural 
Bangalore District, there has been an explosion in population, drawing from far off states in India, putting huge pressure on the general infrastructure and in particular, the healthcare infrastructure. There is a big rise in private sector hospitals, nursing home and 24-hour-care centres.The private hospitals in Bangalore are competing with best Government hospitals as also the best private hospitals of the world.

\section{Objective of the Study}

To measure the quality of healthcare products and service being delivered and to identify factors those influence the patients' and beneficiaries' confidence and comfort level. The key hypothesis is: Relationship management plays a vital role.

\section{Methodology used in the Study}

Extensive literature review done by the researcher stresses the usefulness of the Servqual model and especially the empathy dimension in understanding the crystallization of the concept of service quality. Repeated encounters help establish brand and customer loyalty, which is crucial if Bangalore is to emerge as a hub for medical tourism and telemedicine. This study gives us a snapshot picture of the situation as far as service quality in Bangalore Hospitals and can be used improving service quality and thereby brand loyalty in the future.

We measure service quality using the Servqual model of Parasuraman, on 5 dimensions: Tangibles, Responsiveness Reliability, and Assurance. Empathy by survey method, on a 5 point Likert scale, of sample size 500, on Non random (convenience) Snow Ball sampling method and then analysed using SPSS.

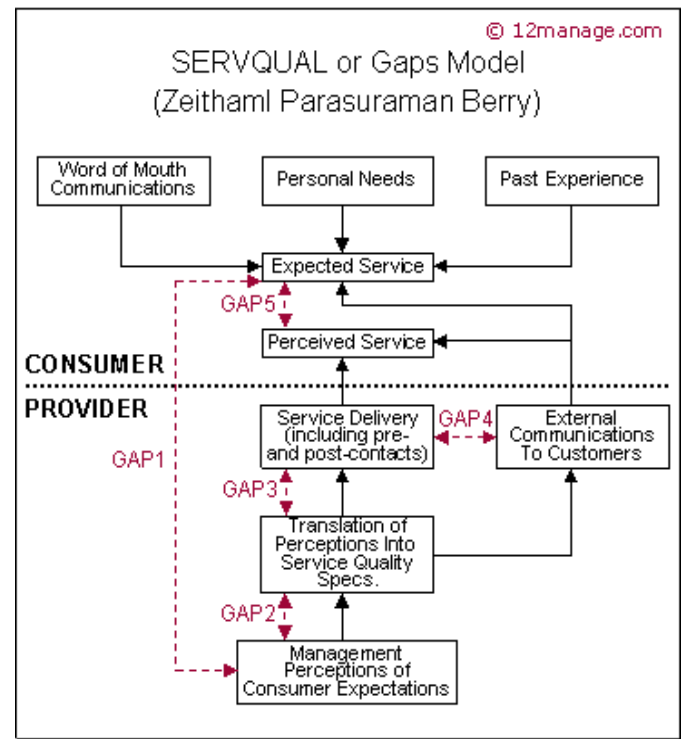

According to Parasuraman et al., Haywood-Farmer (1988) and others, there are three well-documented characteristics of services-intangibility, heterogeneity and inseparability-which must be acknowledged for a full understanding of service quality.

First, services are intangible, because they are performances rather than objects; most services cannot be counted, measured, inventoried, tested or verified in advance of delivery to ensure quality. The main implication of intangibility is that generally one cannot store a service, thus removing the final quality check commonly found in the manufacturing sector.

Second, services have customers with very heterogeneous needs: Consumers of the same service do not all have the same priorities. Consider for example, airline passengers. Different passengers may have different priorities e.g. schedules, schedule reliability, booking arrangements, seat alignments, on-board meals, choice of film, friendliness of flight attendants etc. An analogy may be drawn in the public sector. Within any class room in a school, the particular learning needs of individual students will be different - some will be more numerate or literature than others, and some will have different ambitions for applying the particular knowledge being taught to them. Similarly, in the health sector, some patients crave their own room on hospitalization, whereas others do not want to be on their own.

Third, services have 'inseparability' by which is meant that the production and consumption of services are not separate as they are in manufacturing. As a consequence, in the service industry, quality is not engineered into the product at the manufacturing plant and then delivered intact to the consumer. Rather, quality occurs during the delivery of the service, usually during the interaction between the client and the key contact person from the service provider. In these situations, the consumers' input becomes critical to the quality of the service performance. Indeed, in many service contexts, the customer wishes to participate in creating the 
service. This is certainly true for health, education and social service encounters between professionals and clients as well as for some aspects of government provision. Regarding government provision, whether at the local, provincial or central level, the customer or stakeholder is sometimes intimately involved in the process, for example in planning decisions for housing or industrial development if quality (lack of disagreement) is to be achieved.

It is for these reasons that writers on service quality have defined service as a 'deed', a 'performance' or an 'effort', thus highlighting the inherent importance of the consumer of service having an active involvement in the production or completion of the service process itself.

Following from these features of intangibility, heterogeneity and inseparability, the nature of how quality is evaluated for services is conceived to have a different emphasis from that of manufacturing where quality judgments are essentially responses to tangibles.

\section{SERVICE QUALITY}

Service quality in providing medical solutions has become a competitive advantage as service providers irrespective of government or private. Though the awareness amongst the beneficiaries of medical services has considerably increased, it has not reached all levels. Even today the trust factor plays a vital role in the level of confidence patients have and it varies by individual. Though medical service providers have taken all the factors into consideration, still the concept of "patient is king" as in the case of consumer products where "consumer is king" has not taken root. This is because even today patients are dependent on health care providers. The dependency makes the beneficiaries ignore gaps in service quality.

\section{Service Quality Judgments}

Service quality judgments are considered to be driven by a comparison of consumer expectations with their perceptions of the actual service quality received. Also, this premise of service quality assumes that the judgment of the service received will have combined both evaluation of the outcome of the service and the evaluation of the processes of the service delivery. Hence, for services there is a strong interactive component to the whole aspect of quality, and some have sought to arrive at a general model of the determinants of customers' perception of service quality

- Reliability: e.g. performing the service at the designated time.

- Responsiveness: e.g. willingness to provide the service.

- Competence: e.g. possession of the required skills and knowledge to perform the service.

- Access: e.g. approachability and ease of contact with the providing institution etc.

- Courtesy: e.g. keeping customers informed in language they understand; also listening to them; it means explaining the service; explaining any options or costs; assuring the customer that a problem will be handled

- Credibility: e.g. belief that they have customers' best interests at heart, trustworthiness, honesty, etc.

- Security: e.g. freedom from danger, risk or doubt

- Understanding / knowing the customer: e.g. making the effort to understand the customers' needs by providing individualized attention.

- Appearance / presentation e.g. the physical facilities, the appearance of personnel, tools or equipment used etc.

The determinants of service quality above (based on Parasuraman et al.1985) demonstrate the weight of interactive components in judgments of service quality. It is these interactive properties which have led some to label the nature of quality in the service sector as preferential, so distinguishing it from the objective quality of the manufacturing sector, where quality is in the main associated with the properties of an object which can be measured and demonstrated in a tangible sense. In contrast, quality in the preferential sense is identical not with the properties of an object but rather with the capacity of the properties to achieve a goal, this goal being a state of affairs which is preferred to other states.

\section{Characteristics of excellent customer service (3 R's)}

Excellent customer service should be the aim of all suppliers of products and services. It has the following characteristics:

\section{Responsive:}

Excellent customer service is responsive. A timely response is important. The customer had a requirement when they contacted you and they are likely to have delayed expressing their need. If you delay responding they will solve their problem in some other way. You will have missed an opportunity to serve that customer and the next person they call will probably be one of your competitors. 
Reliable:

Excellent customer service is consistently responsive, with continuously high levels of customer service. The only surprises that customers find welcome and positive are those that improve the service they receive and exceed their expectations. Customers want excellent customer service and they want it every time.

\section{Reliability is heavenly}

Quality is about consistent reliability. I want good service and I want it every time. Quality requires both consistency and reliability. A good friend is a reliable and a consistent friend.

It is costly for employers to deal with queries, recalls, complaints and so on and the same is true for the consumer who is inconvenienced and frustrated by unreliability. Unreliability is not good for either party- buyer or seller- yet it persists in abundance.

On the other hand, companies that can deliver consistent reliability every time at all the time, such as Coca-Cola, will thrive well into the future, because they are just so rare. Reliability is heavenly.

Respectful: Informed, attentive, cheerful, polite and helpful customer service representatives should treat customers with respect.

Excellent customer service is therefore reliable, respectful and responsive.

Why customer service problems exist (3 I's)

Unreliable customer service persists because of the existence of a lack of incentives, a lack of information and a lack of independence.

\section{Research Design}

A total of 540 persons were surveyed with regards to their attitudes towards the service provided by private hospitals in Bangalore. As this is a descriptive study, a random sample was employed to further understand the ratings provided regarding service quality. It must be borne in mind that this is a snapshot in historical time and is likely to change in the fullness of time. At the time of writing, there is a clamour for mechanisms of accountability such as citizen's charter and this is likely to affect the health care sector as well.

\section{Analysis}

The data was analyzed with the help of SPSS statistical package. Though the data consisted mainly of ordinal data, the use of the Likert scale and the moderately large sample size, justified the use of parametric statistics such as correlation and regression. The main dependent variable was Rate Your Hospital, a measure of overall satisfaction with the hospital and the independent variables were the various dimensions of the Servqual scale i.e. Tangibles, Reliability, Assurance, Empathy, and Responsiveness..

\section{Findings}

"Did the Nurse come", a measure of empathy came out as the most important, "Hospital Equipped" (Tangibles), and "Rate your Doctor". (Reliability) as the $2^{\text {nd }}$ and $3^{\text {rd }}$ factors.

\section{Did the Nurse Come}

This is a measure of whether the nurse was easily accessible. In a large, impersonal setting like a hospital, the nurse forms the interface between the hospital and the patient and is consequently crucial in determining rating of service quality. This finding is also echoed in the results of correlation and regression, which shows the importance of nurses in the healing process. In foreign hospitals, nurses are often accorded the status of doctors. In India, this trend has yet to take root. Nurses are often poorly paid and over worked and the profession has yet to find its place in the medical care scenario.

The one factor in which private hospitals outscore public hospitals is empathy.

India's new found wealthy, customers expect to be treated like royalty and are treated accordingly only in private hospitals. The nurse also acts as an interface between customer and hospital and thus is very important from the point of view of customer satisfaction. In fact the physician writer Lewis Thomas is so convinced of the centrality of nurses that he is willing to give them the moon if needs be.

\section{Rate Registration}

The registration desk is the first point where the consumer encounters the hospital and is therefore highly likely to shape customer attitudes. Indians coming out of a long history of socialism, where one had to wait in long queues to register, are likely to pleasantly surprise to encounter a more streamlined registration process. The variable is a measure of ease of registration from very easy to difficult to register. Not surprising, most respondents rated the private hospitals well in terms of registration rate. However, most thought people at 
the registration counter were 'alright' as opposed to nice. There is thus room for improvement, when it comes to staff manning the registration desk

\section{Hospital Well Equipped}

The private sector scores over the public sector in having access to the most modern equipment and technology. They have imported X-ray machines, MRIs, CAT scan machines telemedicine etc. This is because the private hospitals are victims of the import substitution policy that was practiced in the heyday of socialism. The private hospitals are seen are superior in this regard

\section{Suggestions \& Conclusion}

Empirical survey showed that the three dimensions of Empathy (Did the nurse come), Tangibles (Is the Hospital Well Equipped) and Reliability (Rate your doctor) are key factors.

The main recommendation is to take care in the recruitment and training of nurses, on basis of their affection towards people. Nurses, who are highly skilled, should be upgraded as Nurse Practioners and treated and paid on par with doctors.

This study shows how macro and micro factors affect the health care situation and identifies Empathy as a key factor on which private hospitals score over public hospitals. Thus, the main hypothesis of the study, which is that relationship management plays a vital role in the health care system, is validated.

\section{Detailed Recommendations}

1. Since the study underlies the importance of the empathy factor, importance should be given to the recruitment and training of nurses. Nurses are an essential part of the health care process and it is sad to note that they have not got their due in the health care scenario in India. While they enjoy a high status abroad, where as nurse practioners, their status rivals that of doctors, the situation is not the same in India. Here, for many nursing is seen as a low paid, low status job and this needs to change.

2. More attention needs to be paid to the recruitment of nurses. Care should be taken to choose those with a genuine affection for people and not just those who are in it for the money. Since nursing is a caring and demanding profession, it requires professionals of the highest caliber.

3. The salaries paid to those belonging to the nursing profession, should become more comparable to that of doctors. Presently nurses are paid peanuts and this attracts the lowest common denominator to the profession.

4. Continuing education programme should be made available to the nurses. This will improve the quality and care; allow them to take decisions in times of medical emergency, and motivate them further.

5. The hospitals should continue to be equipped with modern equipment, since it is part of the draw of private hospitals. Public hospitals should also equip themselves if they want to continue to attract customers.

6. Public private partnerships should be encouraged. Citizen charters should be set up to establish accountability. Conflicts of interest (such as private doctors participating in the public sector) must be discouraged. This will reduce corruption in this sector.

7. The reliability dimension should be addressed by hiring doctors who not only possess technical skills but abundant affection for people. Doctors may be overworked because of paucity of medical staff in rural areas and primary care. These issues need to be addressed by the government. This is addition to proper consumer redressal mechanisms.

8. Since this is an exploratory study, more studies need to be conducted to further elucidate the concept of service quality. In particular, longitudinal studies that measure the stability of the concept over time as well as the impact of various factors such as gender, education and age need to be taken up.

9. Last but not least, the results show the importance of ayahs and sweepers. These workers may be far down the hierarchy but they play a crucial role in the functioning of the hospital. They not only do their duties but run essential errands for the patients and keep the patients' company. They are an integral part of the hospital's functioning. 
Books:

References:

[1]. Kandampully, J. (1998), Service Quality to Service Loyalty: A Relationship Which Goes Beyond Customer Services, Total Quality Management, Vol. 9, No. 6, pp. 431-443

[2]. Kurtz, D.L. and Clow, K.E. (1998), Service Marketing, John Wiley \& Sons.

[3]. Malhotra, N.K. (2004), Marketing Research: An Applied Orientation, Pearson Prentice Hall.

[4]. Sekaran, U. (2003), Research Methods for Business: A Skill Building Approach, John Wiley \& Sons.www.ibef.org/industry/healthcare.aspx

\section{Journals:}

[5]. Andaleep, S.S. (1998), Determinants of Customer Satisfaction with Hospitals: a Managerial Model, International Journal of Health Care Quality Assurance, Vol. 11, No. 6, pp. 181-187.

[6]. Anderson, E.W., Fornell, C., and Lehmann, D.R. (1994), Customer Satisfaction, Market Share, and Profitability: Findings from Sweden, Journal of Marketing, Vol. 58, pp. 53-66.

[7]. Bloemer, J., Ruyter, K., and Wetzels, M. (1999), Linking Perceived Service Quality and Service Loyalty: a Multi-dimensional Perspective, European Journal of Marketing, Vol. 3 No. 11/12, pp. 1082-1106.

[8]. Caha H: Service Quality in Private Hospitals in Turkey. Journal of Economic and Social Research 2007, 9(1):55-69

[9]. Choi, K.S., Lee, H., Kim, C., and Lee, S. (2005), Service Quality Dimensions and Patient Satisfaction Relationships in South Korean: Comparisons Across Gender, Age, and Types of Service, Journal of Services Marketing, Vol. 19, No. 3, pp. 140-149.

[10]. Dariul J. Messine, Denims J Scotti, Rodney Ganey \& Genevieve Pinto, Joumal of health can Mangaement, May June 2009. The relationship between patient satisfaction and inpatient admissions

[11]. Fornell, C. (1992), A National Customer Satisfaction Barometer: the Swedish Experience, Journal of Marketing, Vol. 56, p. 6-12.

[12]. GrÖnroos, C. (1984), A Service Quality Model and its Marketing Implications, European Journal of Marketing, Vol. 18, No.4, pp. 36-44.

[13]. GrÖnroos, C. (1990), Service Management and Marketing, Lexington Books, Lexington, MA Hasin, M.A.A., Seeluangsawat, R., and Shareef, M.A. (2001), Statistical Measures of Customer Satisfaction for Health Care Quality Assurance, International Journal of Health Care Quality Assurance, Vol.14, No. 1, pp. 6-13.

[14]. Parasuraman, A, Berry, L.L., and Zeithaml, V.A. (1990), An Empirical Test of the Extended Gaps Model of Service Quality, working Paper, No. 90-122, Marketing Science Institute, Cambridge, MA.

\section{Websites}

[15]. www.ibef.org/industry/healthcare.aspx

[16]. healthcare in india. Boston analytics

[17]. www. Indian healthcare. In

[18]. www. irda india.org

[19]. www.technopak.com 